\title{
La ciencia y la Sociedad Económica mallorquina de Amigos del País (1778-1808)
}

\section{Science and the Majorcan Economic Society (1778-1808)}

\author{
Alberto Juan FELANI PINTOS \\ Universidad Nacional de Educación a Distancia \\ afelani1@alumno.uned.es
}

Fecha de recepción: 16-04-2018

Fecha de aceptación: 27-09-2018

\section{RESUMEN}

Durante el período de 1778- 1808 la Sociedad Económica Mallorquina de Amigos del País centró su interés en la ciencia gracias al papel que podían ejercer las innovaciones científicas en el desarrollo económico de Mallorca. La universidad se encontraba inmersa en una profunda reforma dirigida desde la propia monarquía, de ahí la importancia de la Sociedad en el impulso de una serie de proyectos que expresan el auge de las inquietudes en esta materia.

PALABRAS CLAVE: Sociedad Económica Mallorquina de Amigos del País, Mallorca, siglo XVIII, ciencia, Ilustración.

ABSTRACT

During the period 1778 - 1808, the Majorcan Economic Society of Friends of the Country focused its interests on science, thanks to the role which scientific innovations played in the economic development of Majorca. The university found itself immersed in major reform directed by the monarchy. Hence the importance of the Society in the promotion of a series of projects expressing increased concern with subject.

KEY WORDS: The Royal Economic Society, Majorca, XVIII century, science, Enlightement.

\section{INTRODUCCIÓN}

1.1. Tema de investigación, su justificación, ámbito geográfico y cronología

La Sociedad Económica Mallorquina de Amigos del País desde que fue fundada en 1776 se fijó como objetivo fundamental la mejora de las condiciones económicas de la isla. Los ilustrados miembros de la Sociedad se encontraron con la necesidad de acometer 
una serie de proyectos en materia científica, dada la existencia de una serie de carencias en disciplinas como matemáticas, física y química, navegación, geografía o medicina, que lastraba el impulso económico deseado. La universidad española estaba en pleno proceso de reforma, situada al margen de las corrientes académicas europeas, no estaba en condiciones de liderar el desarrollo de la ciencia en el sentido práctico que demandaba la Sociedad. Aunque, en cierta medida, las ideas y propósitos iniciados se toparon con la realidad económica de su financiación, no hay que desmerecer su valor como a continuación se analizará. Todo este espíritu altruista se vio frenado en seco en 1808 con el inicio de la Guerra de la Independencia.

\subsection{Hipótesis de trabajo y objetivos}

En el momento de afrontar el estudio de este tema hay que plantearse cuestiones tales como qué grado de implicación real tuvo la Sociedad en el fomento de la ciencia en la isla, si estas iniciativas fueron aisladas o no, y posteriormente poder valorar la eficacia, o el fracaso, de los proyectos en los que participó. Estas dudas conducen a la formulación de una hipótesis centrada en el argumento de que la SEMAP estuvo involucrada de manera decidida en la puesta en marcha de las escuelas de matemáticas, de física y química, y de pilotaje, en el impulso de la mejora de los caminos de la isla y en la fundación de la Academia médico- práctica, al margen de la universidad, con la finalidad de mejorar el nivel de las técnicas agrícolas, una mayor eficacia de la medicina, y en el aumento del comercio exterior e interior en la isla de Mallorca.

\section{METODOLOGÍA}

\subsection{Fuentes documentales}

La búsqueda y consulta de fuentes documentales primarias se ha realizado en el Archivo del Reino de Mallorca (ARM), donde se encuentra un fondo titulado Sociedad Económica Mallorquina de Amigos del País (SEMAP), y es el que finalmente ha servido de base para este trabajo. Cuando se ha desarrollado el apartado sobre la Academia médicopráctica se han consultado los Documentos Real Academia Médico-Práctica de Mallorca que se encuentran en el Archivo Histórico de la Real Academia de Medicina de las Islas Baleares (AHRAMIB), y a los que se puede acceder a través del Archivo Histórico de la UIB.

\subsection{Estado de la cuestión}

La historiografía no ha tratado de una forma específica y en profundidad la relación que existió entre la ciencia y la Sociedad Económica Mallorquina de Amigos del País desde su fundación en 1778 hasta 1808. M. Ferrer ${ }^{1}$ ha realizado un estudio de carácter general que trata sobre los orígenes, el funcionamiento, las funciones y los objetivos que perseguía la SEMAP. Al igual que el artículo de J. Llabrés ${ }^{2}$ donde cronológicamente relaciona de forma esquemática las actividades de la SEMAP desde su fundación hasta 1917. Apenas sí hay referencias a la ciencia en estos trabajos.

F. Bujosa i Homar llevó a cabo una monografía sobre la Academia médico-práctica de Mallorca (1788-1800)³, donde aquí sí que estamos ante un estudio concreto sobre una

1 M. Ferrer, "La Cofradía de San Jorge y los orígenes de la RSEMAP", Memòries de la Reial Acadèmia Mallorquina d'Estudis Genealògics, Heràldics i Històrics, 10 (2000), pp. 137-170.

2 J. Llabrés, "La Real Sociedad Económica Mallorquina de Amigos del País y sus actividades 1778 a 1917", Boletín de la Sociedad Arqueológica Luliana, XXXIII (1968), pp. 380-391.

3 F. Bujosa i Homar, La Academia Médico-Práctica de Mallorca (1788-1800), Valencia, Cátedra e Instituto de Historia de la Medicina, 1975, pp. 13-31. 
institución promovida por la SEMAP. El papel que la Sociedad desempeña en la promoción de la fundación de la Academia es tratado en un breve espacio de la obra.

La existencia de una Academia de Nobles Artes en el período 1778-1808 ha sido abordada por C. Cantarellas ${ }^{4}$. Aunque la materia objeto de la monografía es el arte, existen breves referencias acerca de fray Miguel de Petra, enseñante de la Escuela de Matemáticas, y sobre los contenidos de los estudios de arquitectura.

A. Ginard5, en el artículo "Antoni Despuig i Dameto, el mapa de Mallorca (1784-1785) i la Societat d'Amics del País" desarrolla con notable acierto el ligamen que existió entre este personaje y la Sociedad. Asimismo, nos presenta las iniciativas de carácter estadístico emprendidas por la Sociedad en 1784 y relaciona un elenco de miembros de la SEMAP que intervinieron en la elaboración del mapa.

Uno de los aspectos que la SEMAP abordó con cierta profusión fue la demografía, tal y como la historiadora I. Moll ha analizado en un destacado estudio sobre esta materia ${ }^{6}$, que puede considerarse un referente en esta materia.

Por último, B. Sureda ${ }^{7}$ se ocupa de los proyectos educativos llevados a cabo por los ilustrados en Mallorca, y en concreto dedica un capítulo monográfico a la concepción que la SEMAP tuvo sobre la educación.

La historiografía no se ha hecho eco de una manera sistemática sobre el pensamiento y las iniciativas que la Sociedad Económico Mallorquina de Amigos del País hubiera podido adoptar en el ámbito de las disciplinas científicas. Ciertamente no podemos generalizar en todas las facetas en las que se puede dividir la ciencia como se ha visto.

\section{EL DESARROLLO DE LA CIENCIA EN EL ÚLTIMO TERCIO DEL SIGLO XVIII EN ESPAÑA}

\subsection{El papel de las Sociedades Económicas de Amigos del País}

La Sociedad Económica Vascongada fue la primera en crearse en 1764 a instancias del conde de Peñaflorida. Sus fines, recogidos en sus statutos, se centraban en "fomentar la agricultura, la industria, el comercio, las artes y las ciencias"8. En contraposición, la SEMAP no cita para nada ni las artes ni las ciencias, se basa en el modelo de la matritense. La Vascongada creó una cátedra de química, una escuela de náutica en San Sebastián y nutrió su biblioteca de obras científicas provenientes del extranjero. Se ocupó de las denominadas ciencias útiles.

Después de transcurridos diez años de su fundación, una circular de Campomanes de 18 de noviembre de 1774, dirigida a las autoridades locales de toda España ordenando fundar sociedades, supuso el punto de partida de la difusión de esta institución. El origen hay que buscarlo en el deseo de Carlos III de fomentar una "cultura nacional con carácter utilitario" ${ }^{\prime \prime}$. Sus preocupaciones principales se centraron en la educación, la agricultura, la

4 C. Cantarellas, "La institucionalización de la enseñanza artística en Mallorca: la Academia de Nobles Artes", Mayurca, 19 (1979), pp. 279-293.

5 A. Ginard, "Antoni Despuig i Dameto, el mapa de Mallorca (1784-1785) i la Societat d'Amics del País", Cuadernos de Geografía, 86 (2009), pp. 241-260.

6 I. Moll, "Modelo de población y política demográfica. La Sociedad Económica Mallorquina de Amigos del País, 1779- 1808", Boletín de la Asociación de Demografía Histórica, XV (1997), pp. 125-163.

7 B. Sureda García, Els il.lustrats mallorquins $i$ els seus projectes educatius, Govern Balear, Palma de Mallorca, 1989.

8 I. Arias de Saavedra, "Las Sociedades Económicas de Amigos del País: Proyecto y realidad en la España de la Ilustración", Obradoiro de Historia Moderna, 21 (2012), p. 222.

9 J. Sarrailh, La España Ilustrada de la segunda mitad del siglo XVII. Madrid. Fondo de Cultura Económica, 1985, p. 252. 
industria y el comercio, mientras que las ciencias tenían valor por su aplicabilidad práctica en la mejora de la economía y de la sociedad. Tenían un carácter utilitario. Basta con percatarse de que ni en Mallorca ni en Valencia dentro de sus comisiones no existía ninguna sobre la ciencia, a diferencia de la del País Vasco. Esto no quiere decir que no se planteasen iniciativas relacionadas con la ciencia, así las academias y escuelas, las publicaciones periódicas, las traducciones de obras extranjeras, la entrega de los premios el día de San Carlos, e incluso la organización de jardines botánicos, como el de Puçol en Valencia son sólo alguno de los ejemplos. En Zaragoza destacó una escuela de matemáticas alentada por Jaime Conde (1782), a la que se unieron pasado un tiempo la cátedra de botánica dirigida por Echeandía y una de química encargada a Otaño.

La alternativa a la universidad para el desarrollo y la enseñanza de las materias científicas habría que buscarla en entidades como el Instituto de Gijón, escuela de mineralogía y náutica alentado por Jovellanos, e inaugurado en 1794, y en las propias Sociedades Económicas. De todas formas, el papel de la ciencia en las Sociedades estaba totalmente supeditado a su aplicación práctica, no era de por sí el fin que perseguían, dado que su orientación era el desarrollo económico local de sectores básicos como la agricultura, la industria y el comercio. La mejora técnica sí que tuvo una mayor proyección, se enfocaba a la mejora de las cosechas, a la fundación de centros técnicos como en Madrid para la producción de lana, algodón, cáñamo y lino, una escuela de máquinas, la metalurgia, la fabricación de aceite, entre otras.

\subsection{La materia científica en la universidad española}

La universidad en España durante la primera mitad del siglo XVIII arrastraba una gran dependencia de la Iglesia y un inmovilismo en los contenidos académicos. Era en palabras de Francisco Aguilar "una institución de enseñanza repetitiva, dogmática, donde se juraba seguir las opiniones del maestro, sin posibilidad de avance científico ${ }^{10 "}$. La ciencia experimental no tenía cabida en las cátedras, y la escolástica se imponía. Carlos III se propuso revertir esta situación. La reforma universitaria se vio favorecida por dos hechos, la reforma de los colegios mayores (1766) y la expulsión de los jesuitas (1767). En 1766 Manuel de Roda y el conde de Aranda encargaron la elaboración de un plan de estudios universitarios a Gregorio Mayans y Siscar. Definitivamente fue desechado, según Peset por su "presteza", se buscaba algo menos radical ${ }^{11}$. Dos años después hay que destacar la Real Cédula de 14 de mayo de 1769, por la que los directores se encargarían de conocer cómo estaba la situación de las universidades y plantear una reforma. Se perseguía mejorar su nivel científico. Se tenían que realizar nuevos planes. Pablo Olavide y el claustro de la Universidad de Sevilla redactaron un plan para la renovación de los estudios y el reparto de las casas pertenecientes a los jesuitas que fue aprobado el 22 de agosto de 1769.

Según Peset ${ }^{12}$ las líneas de los programas relacionadas con el saber científico se caracterizaron por lo siguiente: un nivel científico alejado de la realidad; las ciencias útiles sin lugar en las cátedras; se aconsejaba una concepción diferente de la ciencia y una enseñanza más adyacente al saber enciclopédico; y se pretendía la imposición de la mentalidad ilustrada. Al final del reinado de Carlos III las universidades se podría decir que están controladas y reformadas.

10 F. Aguilar, "La reforma universitaria de Olavide", Cuadernos Dieciochistas, 4 (2003), p. 33.

11 M. Peset y J. L. Peset, La Universidad Española (siglos XVIII y XIX). Despotismo ilustrado y revolución liberal. Madrid. Taurus, 1974, p. 98.

12 Ibídem 
El reinado de Carlos IV estuvo marcado por la Revolución Francesa (1789) y el miedo al contagio de ideas provenientes de más allá de los Pirineos, por esta razón la ciencia española se vio limitada por la censura de los libros, el control de la prensa y la labor de los censores universitarios. Ninguno de los ministros ilustrados como Saavedra, Jovellanos y Urquijo obtuvieron triunfo alguno en el tema de la reforma de la universidad. Godoy se volvió a interesar por las reformas con su primer plan de estudios general para las universidades de 1807, en el que establecía que el de la Universidad de Salamanca tenía que servir como referencia para el resto de universidades. Pretendía un mayor control tanto de las cátedras como de los claustros. El inicio de la Guerra de Independencia paralizó cualquier tipo de reforma, si bien se había conseguido un cierto avance de las ciencias en el seno de la universidad.

\section{LA SOCIEDAD ECONÓMICA MALLORQUINA DE AMIGOS DEL PAÍS Y SUS PROYECTOS ASOCIADOS CON LA CIENCIA DURANTE EL ÚLTIMO CUARTO DEL SI- GLO XVIII}

\subsection{El origen y funcionamiento de la SEMAP}

El origen y funcionamiento de la SEMAP es un tema sobradamente estudiado, por esta razón únicamente es preciso dar unas pinceladas. En el año 1775, la nobleza intentó resucitar la vieja institución de la Cofradía de San Jorge, pero se encontraron con la oposición de Carlos III que rechazó esa pretensión y fomentó la fundación de la Sociedad Económica Mallorquina de Amigos del País. Inaugurada oficialmente el 25 de septiembre de 1778.

Sus miembros formaban parte de una minoría ilustrada, en la que predominaba el sector eclesiástico, miembros de la administración pública, y en menor medida, una parte de la nobleza. El principal rasgo común de las sociedades es su uniformidad, dado que fue promovida directamente por Carlos III, todas ellas disponían de un acto constituyente, un estatuto que seguía el modelo de la Sociedad Económica Matritense de Amigos del País, y el desarrollo de una serie de proyectos en beneficio del interés general. Los estatutos de la SEMAP no difieren de los existentes en otras sociedades. Su objeto es muy claro: "promover la opulencia y felicidad del público en sus ramos de agricultura, industria y comercio ${ }^{13 " .}$ Persiguen de una forma desinteresada el bienestar del pueblo y sus principales preocupaciones van dirigidas a la mejora económica de Mallorca. La ciencia la valoran en su faceta más útil, aquella que puede tener una aplicación en los sectores económicos. La estructura organizativa tenía como base a los socios, y el funcionamiento giraba en torno a las Juntas. Se nombraban unas comisiones por materias (población, agricultura, industria, artes y oficios, comercio y navegación, y pesca), y se nombraban una serie de cargos (director, censor, secretarios, contador y tesorero).

\subsection{El impulso de la ciencia protagonizado por la SEMAP \\ 4.2.1 La Escuela de Matemáticas (1779) y el laboratorio químico de Bartolomé Clar (1801) \\ El origen de la Escuela de Matemáticas de Palma hay que buscarlo en una memoria ${ }^{14}$ de la SEMAP, sin fecha y autor, aunque con casi toda probabilidad sea de 1778 , en la que se defiende la necesidad de constituirla. Es considerada de enseñanza voluntaria y de problemático establecimiento, especialmente por la dotación económica necesaria. Se plantea la fundación de la cátedra sin asignación pecuniaria fija, pero "con ánimo de}

13 M. Ferrer, "La Cofradía de San Jorge...", p. 144.

14 ARM, fondo SEMAP, caja 28, leg. 1, Memoria anónima Escuela de Matemáticas, Palma, s.f. 
permanencia", participaría de los "emolumentos adventicios" como los catedráticos, y las contribuciones propias del estado eclesiástico si así correspondiese. La Sociedad solicita que el monarca otorgue las disposiciones que faciliten su constitución.

Seguidamente, la Sociedad envió una carta ${ }^{15}$ justificativa junto con la memoria citada al Ayuntamiento de Palma y al Patronato de la Universidad Literaria para que estudiasen la conveniencia de su creación. El autor ${ }^{16}$ se lamenta de la falta de compromiso de la Sociedad.

La Sociedad, por consiguiente, recabó la opinión del Ayuntamiento de Palma, pero sobre todo demandó a la Universidad Literaria su beneplácito, con la finalidad de que estableciesen el plan de estudios y se hiciesen cargo del sustento económico. A pesar de que no fuese un referente en la enseñanza de la ciencia, mantenía una indudable autoridad. Todo hace indicar que la Sociedad por sí sola no podía hacerse cargo de los gastos de la escuela.

El 1 de diciembre ${ }^{17}$, la Sociedad, a través de su director, solicitó al superior de la orden de los capuchinos permiso para que Fray Miguel de Petra pudiese impartir clases en la escuela. Miguel Ribot Serra $(1741-1803)^{18}$ era su nombre real, dibujante y arquitecto, estuvo fuertemente vinculado con la SEMAP a lo largo de su vida.

Es digno de mención el interés que dicha apertura tuvo entre los sectores ilustrados, de ahí el ofrecimiento a la SEMAP de Pedro Regaledo Espinosa Cantabrana, subteniente del Real Cuerpo de Artillería, el 15 de enero de $1779^{19}$ para impartir algunas clases en la escuela. Lo hacía en "beneficio común" y como "buen patriota" que se consideraba. Durante el siglo XVIII los mayores avances en la ciencia y la técnica en España estuvieron protagonizados por los cuerpos del ejército formados en las academias militares. No sabemos si su propuesta fue finalmente aceptada e impartió lecciones en la escuela.

No se sabe la fecha exacta de la apertura de la escuela, pero se puede afirmar con cierta seguridad que debió de ser a principios de 1779 , dado que en una carta ${ }^{20}$ dirigida por Manuel de Roda y Arrieta a Antonio Desbrull de fecha 14 de septiembre se congratula de los buenos resultados obtenidos por los alumnos en los exámenes públicos realizados el 4 de julio.

Al parecer, en agosto todavía la SEMAP esperaba respuesta acerca de la concesión de la licencia a Fray Miguel de Petra, por este motivo el 4 de agosto ${ }^{21}$ reiteraron su petición. La respuesta de parte de Fray Juan de Mallorca se hizo esperar hasta el 5 de noviembre ${ }^{22}$, y en ella informa que el capuchino todavía no disponía de la licencia que le tenía que conceder el Padre General de su orden. Finalmente, recibió la licencia solicitada y fue el responsable de la escuela.

15 ARM, fondo SEMAP, caja 28, leg. 1, Solicitud al Ayuntamiento y a la Universidad para que valoren la posibilidad de constituir la cátedra, Palma, s.f.

16 ARM, fondo SEMAP, caja 28, leg. 1, Carta a la SEMAP falta de compromiso para poner en marcha la Escuela de Matemáticas, Palma, s.f.

17 A. Ginard, "Antoni Despuig i Dameto, el mapa...", pp. 10-11.

18 A. Ginard, "Antoni Despuig i Dameto, el mapa...", p. 10.

19 ARM, fondo SEMAP, caja 28, leg. 1, P. Regaledo, Ofrecimiento al SEMAP para impartir clases de matemáticas, Palma, 15 de enero de 1779.

20 C. Manera Erbina, Memorias de la Real Sociedad Económica Mallorquina de Amigos del País, Palma de Mallorca, Lleonard Muntaner Editor, 2014, p. 215.

21 A. Ginard, "Antoni Despuig i Dameto, el mapa...", p. 11.

22 ARM, fondo SEMAP, caja 28, leg. 1, F. Juan, Falta de licencia de Miguel de Petra por el superior de su orden, Palma, 5 de noviembre de 1779. 
La Sociedad decidió el 16 de julio de $1784^{23}$ iniciar un nuevo curso en la escuela debido a la demanda existente, y así se lo comunicó Joseph Desbrull, secretario de la institución, al mismo Miguel de Petra para que se empezasen a colocar carteles informativos. La intención era que el día de San Carlos, aprovechando la entrega de premios los escolares, se examinasen y demostrasen así los avances en este campo. El 31 de ese mismo mes el maestro de Matemáticas ${ }^{24}$ le contestó diciendo que se fijase un día para la apertura de la escuela. Aunque hizo una salvedad, necesitaba un libro de matemáticas con el fin de evitar que los alumnos tomasen apuntes, y así perdiesen el tiempo y se evitase al mismo tiempo la mala letra. Necesitaba además un lugar apropiado y tranquilo y propuso una sala del convento de los capuchinos de Palma por su comodidad y desuso. A. Ginard ${ }^{25}$ nos dice que la escuela empezó allí el 21 de septiembre de 1784.

Podemos afirmar que la escuela cesó en su enseñanza, dado que el 6 de agosto de $1791^{26}$ volvemos a tener noticias acerca de la posibilidad de que el ingeniero Florián Çerich pueda ejercer la cátedra de Matemáticas que se desea establecer en Palma "a imitación de la de Zaragoza". Es posible que problemas de financiación fuesen los causantes del parón. Es curioso que Juan Caballero de la SEMAP hable del establecimiento de nuevo de la cátedra sin hacer referencia a su existencia anterior, y aconseje se base en la fundada en la capital de Aragón. El único inconveniente que su promotor vislumbró es el hecho de que sea oficial del cuerpo de ingenieros.

No se sabe si se llegó a reactivar la escuela, o si quedó en un mero intento. Desde 1778 hasta 1791 el rasgo más destacado es la intermitencia, posiblemente fuesen los problemas de financiación los causantes de la suspensión de su actividad, o bien también es posible que no concurriese una demanda lo suficientemente numerosa como para que se mantuviese la cátedra en funcionamiento. Lo que sí que parece obvio es la preparación académica de los maestros que se postularon, desde Fray Miguel de Petra, reconocido ilustrado mallorquín y muy vinculado a lo largo de toda su vida a la SEMAP, hasta otros de los que tan sólo conocemos su nombre, pero que por su profesión de militar disfrutaban de una reconocida formación científica.

La Sociedad mostró también interés por la química, dado que las aplicaciones prácticas en el campo de la agricultura y la industria son más que evidentes, por ello sus miembros eran conscientes de los beneficios que podrían reportar a la economía mallorquina. En el año 1801 Bartolomé Clar, socio de la SEMAP, a su vuelta de Madrid decidió instalar en una casa contigua a la suya un laboratorio químico. Sin embargo, a causa de la aparición de un presunto heredero del inmueble, el Alcalde Mayor D. Manuel de Denia declaró el bien como mostrenco hasta la resolución de la disyuntiva, y el proyecto se tuvo que paralizar. La Sociedad intercedió en favor de su socio mediante una carta de fecha 5 de noviembre ${ }^{27}$ firmada por Marcos Ygnacio Roselló dirigida a Mario Antonio Togores para que se agilizase el expediente que se encontraba en la Subdirección General de bienes mostrencos. No sabemos nada más, es verosímil pensar que la aspiración no prosperase.

23 ARM, fondo SEMAP, caja 28, leg. 1, J. Desbrull, Nuevo curso de matemáticas, Palma, 16 de julio de 1784. 24 ARM, fondo SEMAP, caja 28, leg. 1, M. Petra, Expone la necesidad de un libro de matemáticas y un sitio adecuado en el convento, Palma, 31 de julio de 1784.

25 A. Ginard Bujosa, “Antoni Despuig i Dameto, el mapa...”, p. 11.

26 ARM, fondo SEMAP, caja 28, leg. 1, J. Caballero, Proposición maestro de la Escuela de Matemáticas, Palma, 6 de agosto de 1791.

27 ARM, fondo SEMAP, caja 31, leg. 14, M. Y. Roselló, Establecimiento de un laboratorio químico dirigido por Bartolomé Clar, Palma, 5 de noviembre de 1801. 


\subsubsection{La escuela de pilotaje (1783-1798)}

La SEMAP era consciente de la necesidad de fomentar el conocimiento de las técnicas de navegación en Mallorca, y de esta forma poder dar un impulso al comercio con el exterior. En el tercer principio de la parte I de las Memorias de la SEMAP de $1784^{28}$ se desarrolla el pensamiento de la institución en materia de comercio exterior y la necesidad de un desarrollo de la marina. El razonamiento se centra en el hecho de que la mayor parte de las mercancías, especialmente aceite, almendras, alcaparras y aguardiente salen de la isla en navíos extranjeros, negando a los isleños unos beneficios que sí les reportaría el traslado de productos en barcos propios, a qué mercados transportarlas, la rentabilidad en el caso de que el pago fuese en especie, el premio del flete, de la comisión y del seguro, y aumentaría la contratación de gente. Estas Memorias ya hablan de la escuela de marina. En 1784 la Escuela de Pilotaje ya existía. Añade que sería interesante poder enviar con una dotación económica suficiente a los alumnos más capacitados a Inglaterra u Holanda para perfeccionarse. Propone el aumento de la plantación de cáñamo que permitiría la fabricación de velas. Se podría incentivar el comercio de la pesca y de las salazones. A la larga redundaría en la importación de todo aquel género que actualmente falta en Mallorca, como la madera, brea y alquitrán. La idea de la enseñanza de las técnicas de navegación siguiendo un plan de estudios moderno en una escuela de navegación estuvo en mente de la institución desde muy pronto.

La Sociedad Económica Vascongada de Amigos del País tuvo interés en fundar una escuela náutica, y la Junta de Comercio de Barcelona puso en marcha una. De igual modo, la SEMAP tal vez siguiendo esta misma tendencia ilustrada se inclinó por materializar la misma idea, conscientes del beneficio que reportaría a la isla. De la documentación ${ }^{29}$ consultada se desprende que desde 1783 hasta 1798 existieron dos intentos de abrir una escuela de navegación, el primero tuvo una vida efímera y duró un año, y el segundo no se podría asegurar si llegó a cristalizar.

Aunque se desconoce la fecha concreta, hay que suponer que en 1783 la Sociedad solicitó información a Onofre Gomila, alférez de fragata jubilado, acerca de cómo funcionaba la Academia de Guardias Marinas de Cartagena, el método de enseñanza aplicado, así como el armamento, libros, material e instrumentos utilizados. Esta Academia fue creada por Carlos III en 1776, y clausurada ya en 1824 tras su traslado a la isla de León (San Fernando, Cádiz). La formación impartida en las academias de Cádiz, El Ferrol y Cartagena se caracterizaron por un riguroso plan de estudios basado en su enfoque científico.

En su respuesta de 3 de diciembre de ese $a$ ño ${ }^{30}$, el alférez de fragata informa a la Sociedad sobre qué materias de estudio son obligatorias (matemáticas, elementos geométricos de Euclides, tratado de trigonometría plana, cosmografía, teoría y práctica de la navegación y maniobra de navío), y la duración diaria de las lecciones fijada en dos horas. La importancia de la Academia radica en que sólo era posible examinarse en el Ferrol, Cádiz y Cartagena por dos maestros y el director del cuerpo de pilotos, y únicamente los alumnos que aprobasen disponían de un certificado para poder navegar. La Sociedad perseguía no sólo preparar en el arte de la navegación a pilotos mallorquines, sino también poder emitir dichos certificados.

La apertura de una escuela de pilotaje no era tarea sencilla, se tenían que cumplir una serie de requisitos básicos para que fuese eficiente y útil. El número de alumnos recomendado

28 C. Manera Erbina, Memorias de la Real Sociedad Económica..., pp. 71-73.

29 ARM, fondo SEMAP, caja 31, leg. 3, Escuela de Pilotaje, Palma, 1783-1797.

30 ARM, fondo SEMAP, caja 31, leg. 3, O. Gomila, Exposición sobre el programa académico y medios técnicos de la Academia de Cartagena, Palma, 3 de diciembre de 1783. 
era de doce, y los conocimientos se deberían impartir dos horas por la mañana y otras dos horas por la tarde. Además, los requisitos mínimos que debería reunir el alumnado serían: saber leer y escribir, ser hijos de padres honrados, y justificar limpieza de sangre. Gomila además adjuntó una relación del armamento y los instrumentos de pilotaje necesarios, su cantidad y precio. Es interesante observar cómo durante el último cuarto del siglo XVIII en Mallorca aún se seguía manteniendo la discriminación a los chuetas a pesar de los intentos reformistas de Carlos III (Real Cédula de 1782). Es evidente que Gomila seguía muy influenciado por esta tradición secular que desde un sector de los ilustrados se quería suprimir, y que continuaba muy arraigada en la sociedad mallorquina.

A finales de 1783 la SEMAP ya estaba en condiciones de valorar el coste económico de tal proyecto. La escuela de pilotaje inició con casi toda probabilidad su singladura en julio de 1784 con Pedro Antonio Padrines como maestro de pilotaje. Esta afirmación surge a raíz de una carta de la SEMAP enviada el 18 de julio de $1785^{31}$ a Padrines en la que ambos comentan que la escuela lleva abierta un año. El maestro ${ }^{32}$ se queja de lo exiguo del subsidio que cobra, y como consecuencia de esto se vería forzado a dejar la enseñanza. Solicitaba a S. M. le concediese empleo perpetuo de piloto práctico en la bahía de Palma para poder compaginar ambas actividades. Antonio Desbrull, en nombre de la Sociedad, reconoce la dificultad de disponer de caudales suficientes para pagarle un salario digno y apoya su solicitud.

Una vez más la Sociedad no puede costear los gastos ocasionados de uno de sus proyectos, esa falta de disponibilidad de dinero lastra la acción ilustrada de esta, y como en el caso de la escuela de Matemáticas considera acertado acudir a otra institución con el objetivo de solventar el desajuste económico, en este caso la concesión por parte de Carlos III de otro empleo que complementase los ingresos que ya tiene.

Finalmente, Padrines solicitó a Pedro Barrientos, ministro principal de Marina del Reino de Mallorca, el puesto de piloto práctico de la bahía de Palma, "obligándose a hacer Escuela de Pilotaje ${ }^{33 "}$. Se compromete a no dejar de impartir las lecciones como requisito para su concesión. Sin embargo, todo hace indicar que su solicitud no prosperó, porque en carta sin datar el interesado muestra su gratitud a la SEMAP, y le solicita un "memorial" para lograr plaza y sueldo y poderse embarcar rumbo a Canarias ${ }^{34}$.

Después de este primer intento, no es hasta el 16 de junio de 1798 cuando Juan Gonzales de Cepeda ${ }^{35}$, persona con experiencia que había estudiado en el Real Colegio de San Telmo de Sevilla, solicita la plaza vacante de enseñante en las escuelas patrióticas en la ciudad de Palma, y además por una gratificación mensual suplementaria, junto con la adquisición de los instrumentos precisos, se ofrece a enseñar el arte de navegar. Los celadores de las escuelas patrióticas, Roselló y Montis y D. Joseph Cotoner, en calidad de secretario de la comisión de comercio de la SEMAP ${ }^{36}$, dan su visto bueno. Todo queda a

31 ARM, fondo SEMAP, caja 31, leg. 3, A. Desbrull, Apoyo de la solicitud de Padrines para que le concedan el cargo de piloto perpetuo, Palma, 18 de julio de 1785.

32 ARM, fondo SEMAP, caja 31, leg. 3, P. A Padrines, Solicitud cargo de piloto práctico de la bahía de Palma, Palma, ¿julio? de 1785.

33 ARM, fondo SEMAP, caja 31, leg. 3, P. A. Padrines, Exposición de méritos y súplica de concesión del cargo de piloto perpetuo, Palma, s.f.

34 ARM, fondo SEMAP, caja 31, leg. 3, P. A. Padrines, Solicitud de "memorial" a la SEMAP para lograr plaza y suelo y embarcarse dirección a Canarias, Palma, s.f.

35 ARM, fondo SEMAP, caja 31, leg. 3, J. González, Solicitud de plaza vacante en las Escuelas Patrióticas y ofrecimiento para enseñar el arte de navegar, Palma, 13 de junio de 1798.

36 ARM, fondo SEMAP, caja 31, leg. 3, J. Cotoner, Contestación de la comisión de comercio de la SEMAP a 
expensas de los Defensores del Colegio de Mercadería sobre la compra de los instrumentos precisos y se ceda el oratorio de la Casa de la Lonja del Mar para la impartición de las lecciones. La institución del colegio tenía una clara función en "el ámbito del fomento y defensa de la mercadería ${ }^{37 "}$ sobre la jurisdicción de policía en el puerto. La Sociedad vuelve a dar muestras de fragilidad económica. Propone a la Casa de Mercadería que se haga cargo de los gastos de la enseñanza y habilite un lugar para dar clase. No podemos saber cómo finalizó el nuevo intento.

\subsubsection{Los estudios de física y química (1798-1800)}

La iniciativa de establecer la enseñanza de física y química provino de Antonio Almodóvar Ruiz Bravo, primer médico del Hospital Militar de Palma, quien presentó el 1 de marzo de 1798 una memoria a la SEMAP ${ }^{38}$ en la que expuso sus motivos. Hace referencia a la protección que otros países ilustrados otorgan a la enseñanza de esta materia y su relación con el ejercicio de las artes. El atraso de la medicina y la cirugía se debe mejorar con el estudio de las ciencias auxiliares, y dentro de estas se encuentra la física y química. Por este motivo Carlos IV ha establecido su enseñanza en diferentes partes de España menos en Mallorca. Este médico impartía en Palma estas materias a ocho discípulos entre médicos y cirujanos por espacio de dos horas asumiendo los gastos de los experimentos realizados. Solicita se le permita el uso del título de profesor, a cambio del compromiso de contestar por escrito cualquier cuestión al respecto que le puedan plantear, a costear de su propio dinero los experimentos, y a admitir a todos aquellos que quieran asistir de forma gratuita.

La SEMAP aceptó su propuesta. En principio no suponía ningún gasto para la Sociedad, aumentaba su prestigio facilitando a médicos y cirujanos el acceso a esta materia básica. La escuela se abrió el 4 de junio de 1798 durante apenas un año. El 28 de septiembre de $1799^{39}$ la escuela ya no tenía actividad, por esta razón el secretario Joseph Zanglada de Togores debía averiguar los motivos. El 25 de octubre ${ }^{40}$ Almodóvar alegó la falta de instrumentos necesarios, entre ellos la máquina neumática de Menorca que no había podido recibir debido a la reconquista inglesa. El secretario de la Sociedad el 21 de febrero de $1800^{41}$ confiaba en que cumpliese el contenido del memorial.

Tres días después, Almodóvar ${ }^{42}$ defendió el cierre alegando la no disponibilidad de los citados instrumentos, el aumento del precio del material de "primera subsistencia" y otros que necesita, y la escasez de caudales para hacer frente a los gastos. A pesar de todo, se muestra receptivo a cualquier proposición que se le haga que permita la viabilidad de la escuela. La SEMAP se vuelve a enfrentar a su mayor problema, la falta de dinero.

la solicitud de la enseñanza del arte de navegar, Palma, 24 de junio de 1798.

37 R. Urgell Hernández: Arxiu del Regne de Mallorca. Guía, Conselleria d'Educació i Cultura del Govern de les Illes Balears, Palma de Mallorca, 2000, p. 48.

38 ARM, fondo SEMAP, caja 31, leg. 4, A. Almodóvar, Memoria sobre la necesidad de establecer los estudios de física y química en Mallorca, Palma, 1 de marzo de 1798.

39 ARM, fondo SEMAP, caja 31, leg. 4, Resolución por la que el secretario debe averiguar las causas de la falta de enseñanza de Almodóvar, Palma, 28 de septiembre de 1799.

40 ARM, fondo SEMAP, caja 31, leg. 4, Resolución Almodóvar, Palma, 26 de octubre de 1799.

41 ARM, fondo SEMAP, caja 31, leg. 4, J. Zanglada, Carta dirigida a Almodóvar manifestando extrañeza por el cierre de la academia, Palma, 21 de febrero de 1800.

42 ARM, fondo SEMAP, caja 31, leg. 4, A. Almodóvar, Justificación del cierre de la academia, Palma, 24 de febrero de 1800. 
La paciencia de la SEMAP se acabó el 11 de marzo. Se dio un plazo hasta el 21 de abril $^{43}$ para que se volviese a abrir la escuela debido a la demanda existente, en caso contrario se iban a pasar los oficios y acuerdos relacionados con este tema a Tomás de Verí con la finalidad de buscar una mediación. No parece que esta prosperase. La Sociedad no estaba dispuesta a su financiación, se aferraba al contenido de la memoria presentada en marzo de 1798 y Almodóvar no podía hacer frente el coste en las condiciones fijadas por él mismo.

\subsubsection{La mejora de los caminos de la isla: la villa de Sóller (1783-1787)}

La SEMAP dentro de sus actividades de carácter geográfico se aplicó en la colaboración y en el apoyo de las iniciativas municipales que estuviesen técnicamente justificadas y que tuviesen como objeto la mejora y realización "ex novo" de caminos, así como en la elaboración de trabajos para conocer su estado y longitud. La finalidad era clara. Todas aquellas acciones que consiguiesen mejorar las comunicaciones interiores de la isla redundaban en beneficios de carácter económico, se ahorraba tiempo en los traslados, y posiblemente se podrían también eliminar los peajes que se cobraban a los arrieros por las mercancías que transportaban, cantidades estas que se usaban para el mantenimiento de los mismos, pero en unas pésimas condiciones. No era efectivo. Los caminos seguían encontrándose en mal estado al poco tiempo.

En $1783^{44}$, la villa de Sóller tenía interés en la construcción de un nuevo camino que pasase desde allí hasta el predio de Alfabia. De esta forma se mejoraría uno de los caminos más transitados de Mallorca dirección Palma, utilizado para el transporte de frutas, en el que se empleaban dos horas, y en el que se había gastado mucho dinero en reparaciones poco eficaces. La obra tenía que ser realizada por peritos y se levantaría un mapa con el camino actual y el proyectado, tal y como se había hecho en Valldemossa. Su realización no debería llevar aparejada una carga "insoportable", sino todo lo contrario, deberían quitarse las actuales por ser gravosas. El mantenimiento del camino se hacía pagando una contribución de seis sueldos por macho y tres por jumento, además de la talla que pagaba la villa. El pedimento recogía un detalle del ahorro que supondría el nuevo camino.

Antonio Cirer y Cardell, inspector de los caminos de la villa de Sóller, tenía la conformidad de los vecinos, y el beneplácito de Pedro Juan Morell, inspector de los caminos de la villa de Valldemossa para ejecutar la obra. Aquel encargaría la traza de la demarcación del actual y del nuevo camino, la tasación del coste de este y de aquel por recomponer el camino del "cruzero" de Buñola hasta el predio de Alfabia. Posteriormente, el ayuntamiento de Sóller tenía que decidir que partidas destinaría al gasto.

Antonio Despuig y Dameto ${ }^{45}$ recibió el encargo de la comisión para medir las millas de los caminos de la isla el 21 de mayo de 1784. El 18 de septiembre presentó "a la junta de la Sociedad un estado de las leguas que contienen los principales caminos de esta Isla ${ }^{46 ",}$ de los que se dirigían a Palma. Estos datos estadísticos permitirían valorar con mejor conocimiento de causa las mejoras, los arreglos, o los proyectos de nuevos trazados. Se perseguía la reducción del tiempo de traslado entre los diferentes puntos de la isla.

Entre la documentación proveniente de la SEMAP se encuentra una referencia al Real Acuerdo del Reino de Aragón de la Instrucción de Caminos de 12 de noviembre de

43 ARM, fondo SEMAP, caja 31, leg. 4, Nuevo plazo, Palma, 11 de marzo a 19 de abril de 1800.

44 ARM, fondo SEMAP, caja 28, leg. 3, Pedimento de la villa de Sóller nuevo camino, Sóller, 1783.

45 ARM, fondo SEMAP, caja 28, leg. 3, A. Despuig, Insta a la comisión a que se reúna en breve, Palma, 21 de marzo de 1784.

46 A. Ginard, "Antoni Despuig i Dameto, el mapa...", p. 248. 
$1785^{47}$. La norma ${ }^{48}$ se ocupaba de los Caminos Reales y Públicos, establecía cómo se debía realizar el mantenimiento, la responsabilidad vecinal, los utensilios de uso y las infracciones y las sanciones pecuniarias aparejadas. El procedimiento administrativo se iniciaba con el expediente del ayuntamiento que incluiría su necesidad y el coste de los peritos, y su pase al corregidor de partido y al caballero intendente.

En 1786 todavía no existían noticias sobre el nuevo camino de Sóller a Alfabia ${ }^{49}$. El nuevo inspector de los caminos, Miguel Frontera, solicita a la Sociedad que, ante el pedimento de la Real Audiencia para que justifique la necesidad del camino, retome el levantamiento de un mapa y calcule las porciones. El inspector presentó a la SEMAP ${ }^{50}$ la Demostración y Apéndice con los contenidos citados, asunto que pasó a Junta extraordinaria el 16 de agosto de 1787, Frontera fue escuchado el 6 de septiembre, y fue aprobado por Real Acuerdo el 9 de octubre.

No sabemos si realmente se llegó a ejecutar la construcción de este camino, o quedó en un proyecto inconcluso. Es lógico pensar que Antonio Cardell, no había encargado finalmente la realización de esta actividad técnico-económica. Desconocemos el motivo. Tal vez esté relacionado con el hecho de que tres años después apareciese otra persona, Miguel Frontera, ocupando su puesto, sin que sepamos tampoco desde cuándo, y quedase pendiente este encargo. Lo cierto es que no se hizo, y el nuevo inspector acudió a la SEMAP, probablemente apelando a su prestigio y sus contactos en la administración, para que se hiciese cargo de la cumplimentación de este trámite asumiendo los gastos que se pudiesen ocasionar, y que justificase los beneficios que reportaría a la villa de Sóller.

\subsubsection{La Academia médico-práctica y el estado de la medicina (1784-1798)}

La Academia médico-práctica se estableció en Palma el 4 de noviembre de 1789, pero hasta llegar a ese momento tuvieron que pasar más de cinco años de actividad desde el 13 de junio de 1784 en la que estuvieron involucrados la SEMAP, la Facultad de Medicina, la Universidad Literaria del Reino de Mallorca y el Ayuntamiento de Palma.

El proyecto de la Academia médico-práctica ${ }^{51}$ fue presentado por un miembro de la propia Sociedad en fecha desconocida del año 1784, seguramente en junio, dado que fue aprobaba por la Junta el 12 de ese mes. Al día siguiente el marqués de Bellpuig, director de la SEMAP, lo envió a Francisco de Togores, rector de la Universidad Literaria del Reino de Mallorca, porque era necesario oír el dictamen del Colegio de Medicina y averiguar qué médicos entrarían voluntariamente a formar parte de ella. Cinco días después se celebró una Junta del colegio ${ }^{52}$ donde los 23 doctores presentes acordaron constituir y entrar a formar parte de la Academia. Este acuerdo fue comunicado el 20 de junio a la Sociedad ${ }^{53}$.

47 ARM, fondo SEMAP, caja 28, leg. 3, conde de Baillet, Se adjunta copia de la Instrucción de Caminos de 1785 para la SEMAP, Palma, 30 de marzo de 1798.

48 http://www.carreteros.org/legislaciona/antigua/anterior_1800/ic1785.htm [Consulta: 17-02-2018].

49 ARM, fondo SEMAP, caja 28, leg. 3, M. Frontera, Reactivar el nuevo camino, Sóller, 1786.

50 ARM, fondo SEMAP, caja 28, leg. 3, M. I. Roselló y O. Gomila, Carta por la que los secretarios de la SEMAP hacen público el Real Acuerdo del camino de Sóller, Palma, 9 de octubre de 1787.

51 ARM, fondo SEMAP, caja 28, leg. 9, marqués de Bellpuig, Información sobre el proyecto de academia, Palma, 13 de junio de 1784 .

52 ARM, fondo SEMAP, caja 28, leg. 9, J. Armengol, Certificado del notario-secretario de la Universidad por el que da testimonio de la constitución de la academia, Palma, 19 de junio de 1784.

53 ARM, fondo SEMAP, caja 28, leg. 9, F. de Togores, Decisión de la constitución de la academia, Palma, 20 de junio de 1784. 
Por el contrario, F. Bujosa i Homar ${ }^{54}$ en su obra La Academia Médico-Práctica de Mallorca (1788-1800) defiende que la proposición se gestó cerca de 1786, casi dos años después de cuando se hizo realmente. No hace referencia a la fecha exacta probablemente porque no consta en los Documentos Real Academia Médico-Práctica de Mallorca que se encuentran en el Archivo Histórico de la Real Academia de Medicina de las Islas Baleares (AHRAMIB), y que son lo que este autor consultó para la realización de su estudio. Además, no cita en apoyo de esta afirmación ninguna fuente documental, como sí hace en sus siguientes aseveraciones. Es posible que considerase el año 1786 como el punto de partida de la Academia debido a su proximidad a la fecha del 11 de diciembre de 1788, cuando se firma la Real Cédula de su creación. Tampoco se encuentra en el AHRAMIB ${ }^{55}$ ninguna referencia a la vaga fecha propuesta por este autor.

La redacción de los estatutos recayó en una comisión de la Facultad de Medicina, compuesta por los doctores en medicina Antonio Vives, Rafael Evinent, Francisco Alemany y Antonio Pablo Togores. El 25 de septiembre de 1784 el rector de la Universidad remitió una copia de los estatutos a la SEMAP ${ }^{56}$. Esta última fecha tampoco coincide con el año 1786 propuesto por F. Bujosa i Homar ${ }^{57}$. El 18 de octubre Joaquín Jacotot ${ }^{58}$ y Juan Bautista Mas $^{59}$ enviaron un pliego al rector de la Universidad Literaria haciendo constar que no iban a firmar los estatutos debido a que contradecían las Constituciones de la Universidad. Las alegaciones realizadas por estos dos médicos serían contestadas el 6 de mayo de 1785, por los mismos redactores del documento ${ }^{60}$.

Su aprobación se demoraba más de lo debido al síndico personero ${ }^{61}$, que tenía encomendado su examen. Finalmente, el Consistorio dio su visto bueno el 23 de noviembre, pero con la condición de que se pudiese variar alguno de los capítulos, previo dictamen de la Universidad Literaria, cosa que hizo dos días después la Junta del Colegio de Medicina ${ }^{62}$.

Parece ser que el 18 de marzo de $1785^{63}$ todavía no se había avanzado en la fundación de la Academia, por esta razón los doctores en Medicina Antonio Vives, Francisco Alemany, Ramón Ballester y Rafael Evinent se dirigieron de nuevo a la SEMAP para que tomase la iniciativa y reactivase el asunto.

Todo hace indicar que los estatutos fueron revisados por la SEMAP, de nuevo por la Universidad Literaria, y finalmente enviados a Carlos III. Según F. Bujosa i Homar ${ }^{64}$ el monarca remitió los estatutos al Supremo Consejo el 20 de agosto de 1787. Este proceso

54 F. Bujosa i Homar, La Academia Médico-Práctica..., p. 16.

55 http://arxiu-historic.uib.cat/index.php/academia-medico-practica-de-mallorca [Consulta: 12-02-2018].

56 ARM, fondo SEMAP, caja 28, leg. 9, F. de Togores, Carta del rector de la Universidad al marqués de Bellpuig por el que se le envía una copia de los Estatutos, Palma, 25 de septiembre de 1784.

57 F. Bujosa i Homar, La Academia Médico-Práctica..., p. 16.

58 ARM, fondo SEMAP, caja 28, leg. 9, J. Jacotot, Pliego remitido al rector de la Universidad, Palma, 18 de octubre de 1784.

59 ARM, fondo SEMAP, caja 28, leg. 9, J. B. Mas, Pliego remitido al rector de la Universidad, Palma, s.f.

60 ARM, fondo SEMAP, caja 28, leg. 9, A. Vives, Contestación a las alegaciones hechas por Jacotot y Mas en contra de los Estatutos de la Academia, Palma, 6 de mayo de 1785.

61 ARM, fondo SEMAP, caja 28, leg. 9, Carta del Síndico Personero por la que indica que tenía que revisar las alegaciones hechas por los médicos, Palma, s.f.

62 ARM, fondo SEMAP, caja 28, leg. 9, J. Bery, Situación de los Estatutos de la Academia, Palma, 13 de diciembre de 1785.

63 ARM, fondo SEMAP, caja 28, leg. 9, A. Vives, Carta por la que una serie de doctores en medicina solicitan a la SEMAP se ponga en marcha la academia, Palma, 18 de marzo de 1785.

64 F. Bujosa i Homar, La Academia Médico-Práctica..., p. 16. 
culminó con la firma de la Real Cédula el 11 de diciembre de 1788 por la que se constituía la Academia médico-práctica. A continuación el 16 de mayo de $1789^{65}$ los doctores en Medicina Antonio Vives, Francisco Alemany, Ramón Ballester y Rafael Evinent solicitaron permiso al rector de la Universidad para que se reuniesen los médicos y la comisión de la Sociedad en el oratorio privado para ejecutar la Real Cédula. F. Bujosa i Homar ${ }^{66}$ relata que el 23 de mayo Juan Pérez Villamil e Ignacio Serra, comisionados por la Sociedad, y el notario Francisco Alemany reunieron en las casas consistoriales de Palma a los médicos que se inscribieron como académicos y eligieron los cargos. Por último, su consumación se produjo el 4 de noviembre siguiente con la celebración de la primera Junta.

La institución recién creada tenía dificultades para conseguir una dotación económica que cubriese los gastos indispensables, por este motivo solicitan el 27 de diciembre a Carlos IV una asignación de 3.000 reales anuales con la finalidad de hacer frente los pagos de escritorio y secretaría, libros, muebles y utensilios, correspondencia, instrumentos científicos, además de los ocasionados por los trabajos facultativos en la isla con la pretensión de no pagar un salario, pero sí de que no financien estas actividades con su patrimonio ${ }^{67}$. Poco después la situación continuaba igual, por esta razón Joseph Llabrés y Francisco Alemany, vicepresidente y secretario de la Academia respectivamente, solicitan a la SEMAP la dotación económica que se considerase oportuna, dado que todavía estaba pendiente la contestación del Real Consejo a la solicitud de la asignación que se hizo al monarca ${ }^{68}$.

La Academia médico-práctica dejó de funcionar en el año 1800 tras doce años de funcionamiento.

EI interés de la SEMAP por la medicina continuó más allá de la Academia médicopráctica. Entre finales de septiembre y principios de octubre de 1798 el Intendente Josef de Laudenes presentó una memoria a la SEMAP ${ }^{69}$ en la que mostraba su excepticismo con la reforma de la medicina. El plan de estudios en las universidades se basaba en el método filosófico y en la imaginación, no en la práctica, culpando de esta situación al egoísmo de los médicos. La gente por ignorancia no creía en la eficacia de otro método de curación que no se sustentase en la costumbre. La única solución factible era hacer frente a la ignorancia con la erudición.

El 17 de octubre de $1798^{70}$ el segundo censor Sr. Cotoner da su visto bueno a la memoria. El 30 de octubre ${ }^{71}$ es leído en Junta extraordinaria, y el Sr. Togores indica a los socios doctores en Medicina, Rafael Evinent y Antonio Pablo Togores, emitan dictamen sobre la procedencia de que se entregase un premio a quien resolviese el problema planteado en este documento antes del 3 de noviembre, debido a que el 4 se han de abrir las carpetas de los papeles que se hubieran premiado.

65 ARM, fondo SEMAP, caja 28, leg. 9, A. Vives, Carta al rector de la Universidad solicitando permiso para reunirse con la SEMAP para poner en marcha la Academia, Palma, 16 de mayo de 1789.

66 F. Bujosa i Homar, La Academia Médico-Práctica..., p. 16.

67 ARM, fondo SEMAP, caja 28, leg. 9, Carta de la Academia por la que informan sobre los gastos que conlleva y la asignación de 3000 reales solicitada a monarca, Palma, 27 de diciembre de 1789.

68 ARM, fondo SEMAP, caja 28, leg. 9, J. Llabrés y F. Alemany, Solicitud de la Academia de dotación económica a la SEMAP, Palma,10 de julio de 1790.

69 ARM, fondo SEMAP, caja 31, leg. 25, J. de Laudenes, Memoria sobre el estado actual de la medicina en Mallorca proponiendo un nuevo sistema de curación, Palma, 1798.

70 ARM, fondo SEMAP, caja 31, leg. 25, Censor Sr. Cotoner, Palma, 17 de octubre de 1798.

71 ARM, fondo SEMAP, caja 31, leg. 25, Dictamen entrega de premio, Palma, 30 de octubre de 1798. 
La Sociedad siempre estuvo relacionada con el patrocinio de acciones vinculadas con la sanidad, incluso con los estudios en veterinaria. En Madrid en 1793 Carlos IV había fundado un Colegio de Veterinaria. En $1799^{72}$ se tenían que cubrir cuarenta plazas, y la SEMAP decidió publicar el 1 de julio una Hoja de Noticias publicitándolo porque había falta de veterinarios en Mallorca. Los requisitos eran disfrutar de una "salud robusta" y tener entre 16 y 22 años. Se valorarían también ser hijos de maestros albéitares, aquellos que tuviesen nociones de medicina, física, gramática latina y alguna lengua extranjera. Se presentaron dos candidatos ${ }^{73}$, Juan Batle, de 17 años, con algunos conocimientos en veterinaria, había estudiado dos años Gramática Latina, pero tenía dificultades para leer en castellano, mientras que Miguel Manresa, de 18 años había cursado estudios de Gramática Latina, dos años de Retórica y un año de principios de albeitería. Este último fue presentado como candidato idóneo para entrar en la Escuela de Veterinaria.

\section{CONCLUSIONES}

La Sociedad Económica Mallorquina de Amigos del País durante el período comprendido entre 1778 y 1808 impulsó diferentes proyectos vinculados con la ciencia. Buscaba una mejora en el comercio tanto interior como marítimo, la mejor preparación de médicos y cirujanos con conocimientos en física y química, el progreso de la asistencia sanitaria al margen de los métodos más tradicionales y anquilosados, la disponibilidad de veterinarios bien preparados, la adopción de conocimientos en química para la mejora de la agricultura y la industria, la mejora de los caminos, en definitiva intentaba cubrir la carencia de estudios científicos modernos que la universidad no proporcionaba.

La implicación de la Sociedad es incuestionable. Sus contactos con las principales instituciones mallorquinas como el Ayuntamiento de Palma, la Real Audiencia y la Universidad Literaria, eran fluidos. Solicitaron opiniones cualificadas acerca de diversos proyectos, y los maestros seleccionados para la enseñanza de matemáticas, física y química, y navegación formaban parte de los elementos mejor preparados de la sociedad mallorquina.

Intenciones muchas, es innegable, pero otra cosa muy distinta es poder afirmar que todos estos proyectos iniciados fuesen eficaces y útiles. Las diferentes escuelas de matemáticas, física y química, y pilotaje no gozaron de continuidad. Incluso el proyecto más ambicioso en el que participó, la Academia médico-práctica, únicamente sobrevivió desde 1788 a 1800. El principal problema que impide a la SEMAP culminar con éxito todas estas iniciativas es la falta de dinero, no lograban mantener una infraestructura con cierta garantía, de ahí que buscasen apoyo económico, incluidos oficios y rentas del monarca.

Los esfuerzos realizados por la Sociedad se centraron en aquellas actividades estrechamente vinculadas con la agricultura, la industria y el comercio, por esta razón la ciencia quedaba en un papel subordinado.

Realmente la SEMAP estuvo involucrada de manera decidida en diferentes proyectos relacionados con la promoción del estudio de la ciencia, la escuela de matemáticas, de física y química, y de pilotaje, en el impulso de la mejora de los caminos de la isla y en la fundación de la Academia médico-práctica, pero su mayor obstáculo fue la falta de financiación que a corto y medio plazo lastró la continuidad de sus iniciativas. Es obvio que actuó al margen de la Universidad Literaria en determinadas materias, como en la fundación de la escuela de pilotaje, o en la de física y química, pero también es cierto que tuvo que contar con ella en ciertos momentos en los que no podía prescindir de su autoridad, como en la

72 ARM, fondo SEMAP, caja 31, leg. 6, J. Zanglada, Hoja de noticias impresas por la SEMAP por el que se anuncian las plazas del Colegio de Veterinaria, Palma, 1 de julio de 1799.

73 ARM, fondo SEMAP, caja 31, leg. 6, J. Vidal y M. A. Togores, Elección de Miguel Manresa como candidato para la Escuela de Veterinaria, Palma, 4 de agosto de 1799. 
constitución de la escuela de matemáticas o la Academia médico-práctica. Eran conscientes de que sin su consentimiento y complicidad no hubiesen podido sacar la idea adelante. Es notorio que la intención perseguida era conseguir un progreso técnico que tuviese un beneficio económico. Todas estas actividades tenían una evidente finalidad práctica, la mejora del comercio marítimo con la disponibilidad de pilotos avezados en el arte de la navegación, el progreso del comercio interior con la disponibilidad de una adecuada red de caminos, el cuidado del ganado con veterinarios bien adiestrados, la mejora agrícola con químicos instruidos, la adecuada y más moderna asistencia sanitaria, en definitiva se perseguía el progreso de los sectores económicos básicos de la isla de Mallorca.

En conclusión, ¿podemos hablar de éxito o fracaso de la SEMAP? La respuesta no puede ser unívoca, no es posible contestar sí o no. Si nos atenemos a los resultados está claro que no fueron los esperados por estos ilustrados, pero también hay que añadir que sus iniciativas persiguieron unos avances científicos y técnicos inexistentes en Mallorca. Algo empezaba a cambiar.

\section{BIBLIOGRAFÍA}

Aguilar, F., "La reforma universitaria de Olavide", Cuadernos Dieciochistas, 4 (2003), pp. 31-46.

Amengual, J., "La preilustración en los medios eclesiásticos de Mallorca (ss. XVII-XVIII)", Hispania, 212 (2002), pp. 907-956.

Arias de Saavedra, I., "Las Sociedades Económicas de Amigos del País: Proyecto y realidad en la España de la llustración", Obradoiro de Historia Moderna, 21 (2012), pp. 219245.

Bertomeu, J. R. y García, A., "La química aplicada a las artes y la Real Sociedad Económica de Amigos de País de Valencia (1788- 1845)", en Ilustración y Progreso: La Real Sociedad Económica de Amigos del País de Valencia (1779-2009). Valencia. Real Sociedad Económica de Amigos del País de Valencia, 2010, pp. 321-356.

Bujosa, F., La Academia Médico-Práctica de Mallorca (1788-1800), Valencia. Cátedra e Instituto de Historia de la Medicina, 1975.

Cantarellas, C., La Lonja de Palma, Govern Balear. Palma de Mallorca, 2003.

Cantarella, C., "La institucionalización de la enseñanza artística en Mallorca: la Academia de Nobles Artes", Mayurca, 19 (1979), pp. 279-293.

Cortés, J. M., "Notas sobre la sanidad marítima mallorquina en el siglo XVIII". BSAL, 57 (2001), pp. 163-170.

Cortijo, A., "De la Sentencia- Estatuto de Pero Sarmiento a la problemática chueta (Real Cédula de Carlos III,1782)", EHumanista, 21 (2012), pp. 483-533.

Fernández, F. J., Los ideales científicos y políticos de los marinos ilustrados españoles del siglo XVIII, Universidad Complutense de Madrid, 2014, Tesis doctoral inédita.

Ferrer, M., "La Cofradía de San Jorge y los orígenes de la RSEMAP", Memòries de la Reial Acadèmia Mallorquina d'Estudis Genealògics, Heràldics i Històrics, 10 (2000), pp. 137-170.

Ferrer, M., "Un reformador político del Antiguo Régimen (José Desbrull y Boil de Arenós)", Memòries de la Reial Acadèmia Mallorquina d'Estudis Genealògics, Heràldics $i$ Històrics, 11 (2001), pp. 107-148.

Ginard, A., "Antoni Despuig i Dameto, el mapa de Mallorca (1784-1785) i la Societat d'Amics del País", Cuadernos de Geografía, 86 (2009), pp. 241-260.

González, F., "Jorge Juan innovador de la Educación Superior en la España ilustrada", Revista Complutense de Educación, 19 (2008), pp. 115-135.

Longás, A., "Las fuentes documentales para el estudio de los espacios docentes de la 
Universidad de Mallorca en el siglo XVIII", en Imatges de l'escola, imatge de l'educació. Actes de les XXI Jornades d'Història de l'Educació, Palma de Mallorca, 2014, pp. 435448.

Manera, C., Memorias de la Real Sociedad Económica Mallorquina de Amigos del País, Palma de Mallorca, Lleonard Muntaner Editor, 2014.

Moll, I., "Modelo de población y política demográfica. La Sociedad Económica Mallorquina de Amigos del País, 1779- 1808", Boletín de la Asociación de Demografía Histórica, XV (1997), pp. 125-163.

Moll, I., "Algunos aspectos de la organización de la asistencia sanitaria en la Mallorca rural, siglos XVIII y XIX", Florianópolis, 14 (2005), pp. 469-479.

Palma, D., "Una faceta de la política educativa llevada a cabo por los ilustrados de la Real Sociedad Económica Matritense de Amigos del País, durante los reinados de Carlos III y Carlos IV", Hispania, 157 (1984), pp. 321-342.

Pérez, G., "Ciencia y divulgación científica en las Sociedades Económicas a fines del siglo XVIII. El caso de la Real Sociedad Económica Aragonesa", en Estado actual de los estudios sobre Aragón vol. II. Actas de las segundas jornadas en Huesca, Zaragoza, 1979, pp. 707-711.

Perrupato, S., "Antiguos y modernos en la universidad española de la segunda mitad del siglo XVIII. Avances de secularización en el plan de reforma universitaria elaborado por Gregorio Mayans y Siscar (1767)", Historia y Sociedad, 27 (2014), pp. 165-188.

Peset, M. y Peset, J. L., La Universidad Española (siglos XVIII y XIX). Despotismo ilustrado y revolución liberal, Madrid. Taurus, 1974.

Poy, R., "Regeneración educativa y cultural de la España Moderna: reformas monárquicas en educación y el papel de los obispos de la llustración en el siglo XVIII", Cuadernos Dieciochistas, 10 (2009), pp. 185-217.

Sánchez, J. F. y Candel, M., "El observatorio astronómico de la Academia de Guardias Marinas de Cartagena", Llull: Revista de la Sociedad Española de Historia de las Ciencias y de las Técnicas, 17 (1994), pp. 343-356.

Sarrailh, J., La España Ilustrada de la segunda mitad del siglo XVII, Madrid, Fondo de Cultura Económica, 1985.

Sureda, B., Els il.Iustrats mallorquins i els seus projectes educatius, Govern Balear, Palma de Mallorca, 1989.

Urgell, R., Arxiu del Regne de Mallorca. Guía, Conselleria d'Educació i Cultura del Govern de les Illes Balears, Palma de Mallorca, 2000. 